\title{
Rational modulator design by exploitation of protein- protein complex structures
}

Citation for published version (APA):

Wichapong, K., Poelman, H., Ercig, B., Hrdinova, J., Liu, X., Lutgens, E., \& Nicolaes, G. A. F. (2019).

Rational modulator design by exploitation of protein-protein complex structures. Future Medicinal Chemistry, 11(9), 1015-1033. https://doi.org/10.4155/fmc-2018-0433

Document status and date:

Published: 01/05/2019

DOI:

10.4155/fmc-2018-0433

Document Version:

Publisher's PDF, also known as Version of record

Document license:

Taverne

Please check the document version of this publication:

- A submitted manuscript is the version of the article upon submission and before peer-review. There can be important differences between the submitted version and the official published version of record.

People interested in the research are advised to contact the author for the final version of the publication, or visit the DOI to the publisher's website.

- The final author version and the galley proof are versions of the publication after peer review.

- The final published version features the final layout of the paper including the volume, issue and page numbers.

Link to publication

\footnotetext{
General rights rights.

- You may freely distribute the URL identifying the publication in the public portal. please follow below link for the End User Agreement:

www.umlib.nl/taverne-license

Take down policy

If you believe that this document breaches copyright please contact us at:

repository@maastrichtuniversity.nl

providing details and we will investigate your claim.
}

Copyright and moral rights for the publications made accessible in the public portal are retained by the authors and/or other copyright owners and it is a condition of accessing publications that users recognise and abide by the legal requirements associated with these

- Users may download and print one copy of any publication from the public portal for the purpose of private study or research.

- You may not further distribute the material or use it for any profit-making activity or commercial gain

If the publication is distributed under the terms of Article $25 \mathrm{fa}$ of the Dutch Copyright Act, indicated by the "Taverne" license above, 


\section{UvA-DARE (Digital Academic Repository)}

\section{ADAMTS13 and thrombotic thrombocytopenic purpura}

On the edge between hemostasis and autoimmunity

Hrdinová, J.

\section{Publication date}

2021

Document Version

Other version

License

Other

Link to publication

Citation for published version (APA):

Hrdinová, J. (2021). ADAMTS13 and thrombotic thrombocytopenic purpura: On the edge between hemostasis and autoimmunity.

\section{General rights}

It is not permitted to download or to forward/distribute the text or part of it without the consent of the author(s) and/or copyright holder(s), other than for strictly personal, individual use, unless the work is under an open content license (like Creative Commons).

\section{Disclaimer/Complaints regulations}

If you believe that digital publication of certain material infringes any of your rights or (privacy) interests, please let the Library know, stating your reasons. In case of a legitimate complaint, the Library will make the material inaccessible and/or remove it from the website. Please Ask the Library: https://uba.uva.nl/en/contact, or a letter to: Library of the University of Amsterdam, Secretariat, Singel 425, 1012 WP Amsterdam, The Netherlands. You will be contacted as soon as possible. 


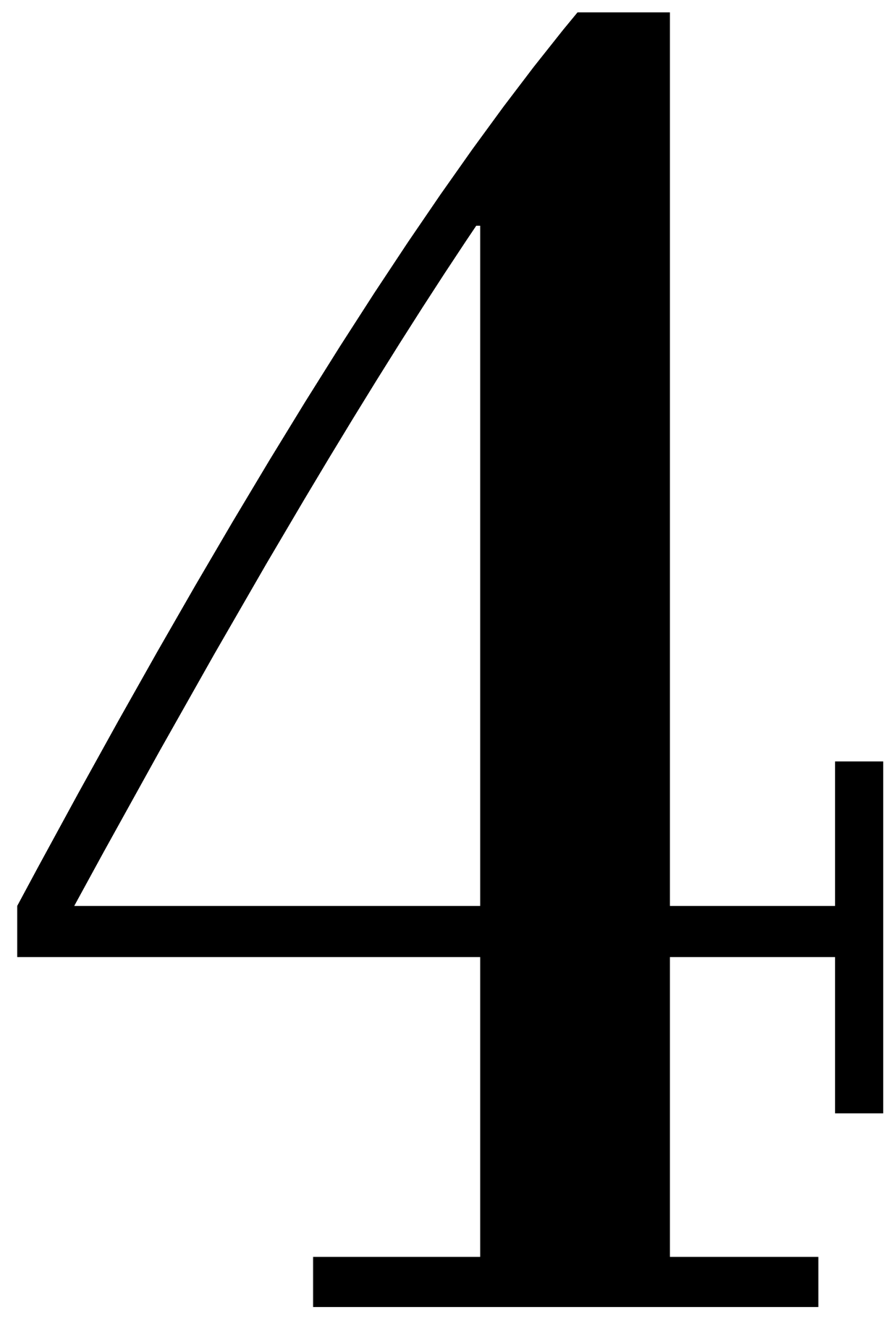




\section{Chapter 4}

\section{Rational modulator design by exploitation of protein-protein complex structures}

Kanin Wichapong, Hessel Poelman*, Bogac Ercig*, Johana Hrdinova*,

Xiaosong Liu*, Esther Lutgens \& Gerry A.F. Nicolaes

*These authors contributed equally

Future Medicinal Chemistry 2019; 11(9):1015-1033 


\section{ABSTRACT}

The horizon of drug discovery is currently expanding to target and modulate proteinprotein interactions (PPIs) in globular proteins and intrinsically disordered proteins that are involved in various diseases. To either interrupt or stabilize PPIs, the 3D structure of target protein-protein (or protein-peptide) complexes can be exploited to rationally design PPI modulators (inhibitors or stabilizers) through structurebased molecular design. In this review, we present an overview of experimental and computational methods that can be used to determine 3D structures of protein-protein complexes. Several approaches including rational and in silico methods that can be applied to design peptides, peptidomimetics and small compounds by utilization of determined 3D protein-protein/peptide complexes are summarized and illustrated. 
Protein-protein interactions (PPIs) are at the very basis of function in biological systems as they essentially connect the players that are involved and perform important roles in virtually all biological pathways, including signal transduction, immune recognition, transmembrane transport, cell-cell interactions, post-translational modification and maintenance of cellular organization. ${ }^{1}$ Inevitably, reflecting their pivotal importance, PPIs are involved in the etiology of numerous diseases, for example, cancer, infectious diseases, inflammatory diseases, neurodegenerative diseases and autoimmune diseases. ${ }^{2-6}$ Despite the recognized importance of proteins as target for pharmacotherapy, PPIs per se have long been neglected as potential drug targets for targeting by drug-like inhibitors, mainly due to the supposedly undruggable flat and large interfaces between the protein partners in the protein-protein complexes. PPI interfaces vary from 1000 to $3000 \mathrm{~A}^{2}$ whereas typical binding pockets in proteins are comparatively small (around 300-1000 A ). $^{7-9}$ However, the PPI research field is undergoing rapid development and receives growing interest as evidenced by the fact that during the last 20 years novel peptides, peptidomimetics and small compounds have been increasingly discovered and developed to inhibit or stabilize PPIs. ${ }^{710-13}$ The number of PPI modulators is likely to increase, considering that only a small proportion of the PPIs from the estimated 650,000 different protein-protein complexes identified in the human interactome have been targeted through drug discovery. ${ }^{9}, 14$ Thus, there are still vast numbers of PPIs that have not yet been explored and targeted for drug development. Not only well-defined protein-protein surfaces are being targeted, recently, the horizon of drug discovery research field has been expanded to target also unstructured proteins that play essential roles in PPIs. Development of novel inhibitors binding to intrinsically disordered proteins (IDPs) or intrinsically disordered protein regions (IDPRs) such as in C-Myc ${ }^{15,16}$, amyloid- $\beta$ peptide ${ }^{17}$ and histone ${ }^{18}$ are examples to prove the concept of IDPs and IDPRs as being druggable and promising targets. Another example is compound MSI-1436 which binds to the disorder C-terminus of PTP1B. This compound is now entering clinical trial phases for treating breast cancer, obesity

and diabetes ${ }^{19,20}$ confirming the principle of concept that targeting disordered proteins is feasible. Therefore, development of small compounds or peptides to target either the interfaces or the unstructured parts of protein binding partners, in order to interrupt or stabilize PPIs, represents a promising future trend in drug discovery research.

Although inhibitors and stabilizers of PPIs can bind at the proximal subpockets at the interface such as in the case of 14-3-3 protein ${ }^{21}$ and it seems that they likely have common features for binding and interacting with protein-protein complexes, recent studies have shown that small molecule stabilizers possess different physiochemical properties than inhibitors. ${ }^{11,22}$ Nevertheless, despite the heterogeneity in the small molecules themselves, similar common approaches can be applied to develop PPI modulators, being either inhibitors or stabilizers. PPI modulators can be subdivided in two different 


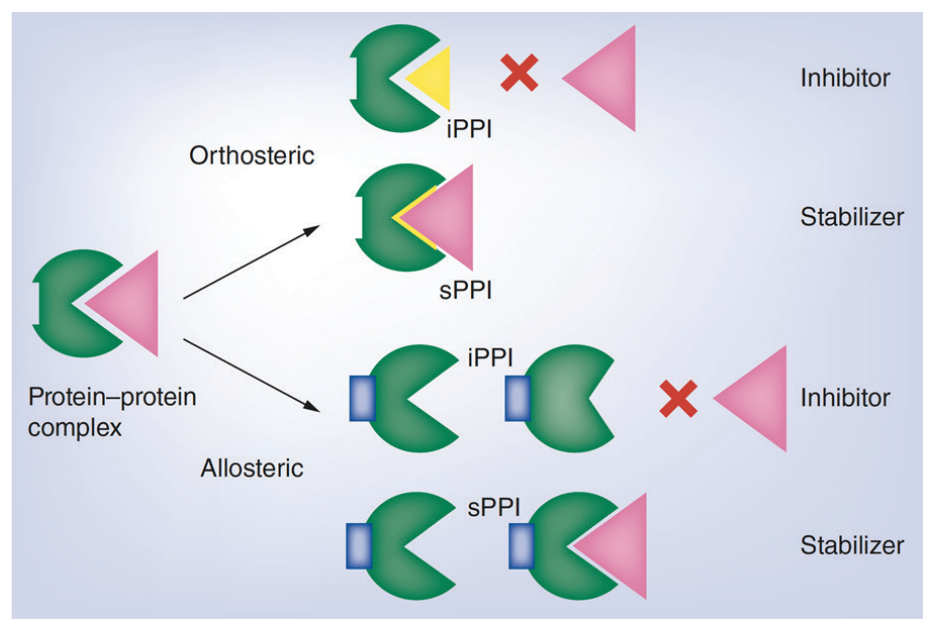

Figure 1. Different strategies to modulate protein-protein interactions. Modulation of PPIs by interactions of inhibitors (iPPI) or stabilizers (sPPI) at the orthosteric or allosteric pocket of the protein-protein complex. ${ }^{2,23,24}$ PPI: Protein-protein interaction; iPPI: Inhibitor PPI; sPPI: Stabilizer PPI.

classes, depending on the type of interface involved. Modulation of PPIs can be done by development of compounds binding at an orthosteric interface (a pocket located between the interfaces of two proteins) or at an allosteric pocket (a distant pocket from the interface of two interacting proteins) $)^{2,23,24}$ as shown in Figure 1. Orthosteric modulators regulate PPIs either by functioning as inhibitors PPI (iPPI) to disrupt PPIs to prevent complex formation between two proteins or, on the other hand stabilizers PPI (sPPI), they have different roles by functioning as molecular glue to connect and stabilize two proteins which can consequently promote the function of protein heteromers. In contrast, allosteric modulators control PPIs by binding at the allosteric pocket which subsequently can induce a conformational change of the binding proteins, resulting in the prevention (iPPI) or enhancement (sPPI) of PPIs. Targeting allosteric pockets is attractive, as large molecules may not be required for binding an allosteric pocket in order to change the protein conformation but this strategy still remains a nontrivial task. ${ }^{24,25}$ In contrast, the orthosteric protein interface provides interaction information of the proteins involved which can be more readily utilized to rationally design orthosteric modulators mimicking these critical interactions. ${ }^{24}$

Next to a division based on the property of the interfaces, PPIs can also be divided into different structural classes depending on the type of binding partner involved. Thus, we can distinguish PPIs formed by complexation of two globular proteins, by binding of a single peptide chain, disordered proteins or unstructured protein regions to a globular protein or by peptide-peptide complexes (as shown in Figure 2) ${ }^{26}$, with the molecular 
shapes of interfaces and interactions between the binding partners being different for these classes. For example, interfaces between globular proteins are mostly flat and large and interactions at such interfaces are mainly hydrophobic, which typically is driven by a ring of polar residues around the interface. A mixture of hydrophobic and polar interactions and water molecules at interface is also another type of interactions at the interface between two globular proteins. ${ }^{26-28}$ On the other hand, interactions between two unstructured peptides such as IDPs or IDPRs are predominantly driven by electrostatic interactions. ${ }^{29,30}$ Thus, identification of these PPI structural classes can be helpful to design specific types of inhibitors or stabilizers for particular PPIs. Development of compounds to modulate PPIs can be done by using different drug discovery approaches such as phenotypic screening ${ }^{31}$, target-based (or high-throughput) screening and structure-based design. ${ }^{24}$ In this review, we will focus mainly on structure-based design approaches as we have applied this method to successfully identify and develop novel inhibitors for different classes of PPIs. ${ }^{32-38}$

Structure-based PPI modulator design relies on knowledge of the 3D structure of the complex of target molecules, where, for example, a protein-protein complex structure will provide information on detailed atomistic interactions between the interfaces of two proteins. This information can be utilized to rationally design small compounds, peptides or peptidomimetics to inhibit or stabilize PPIs. Therefore, whether the aim is to develop inhibitors or stabilizers for PPIs, identification of a targeted complex is a first and crucial step toward success in structure-based molecular design for PPIs. Several methods ranging from a simple and inexpensive method such as molecular docking to the advanced technologies like cryo-electron microscopy (cryo-EM) ${ }^{39-41}$ can be applied for this purpose. In this review, we present an overview of recent methods and technologies that are applied to identify protein-ligand or protein-protein complexes. This includes both experimental and predictive in silico methods. Moreover, an overview will be given of computational and rational methods employed to design compounds (peptides, peptidomimetic and small compounds) that should either inhibit or stabilize PPIs. Finally, examples will be given for the various classes of PPI modulators where novel inhibitors or stabilizers which were successfully developed by specific incorporation of 3D structures of protein-protein or protein-ligand/peptide complexes providing insight into key important interactions at interface which can be used for rationally design and development of bioactive PPI modulators. 


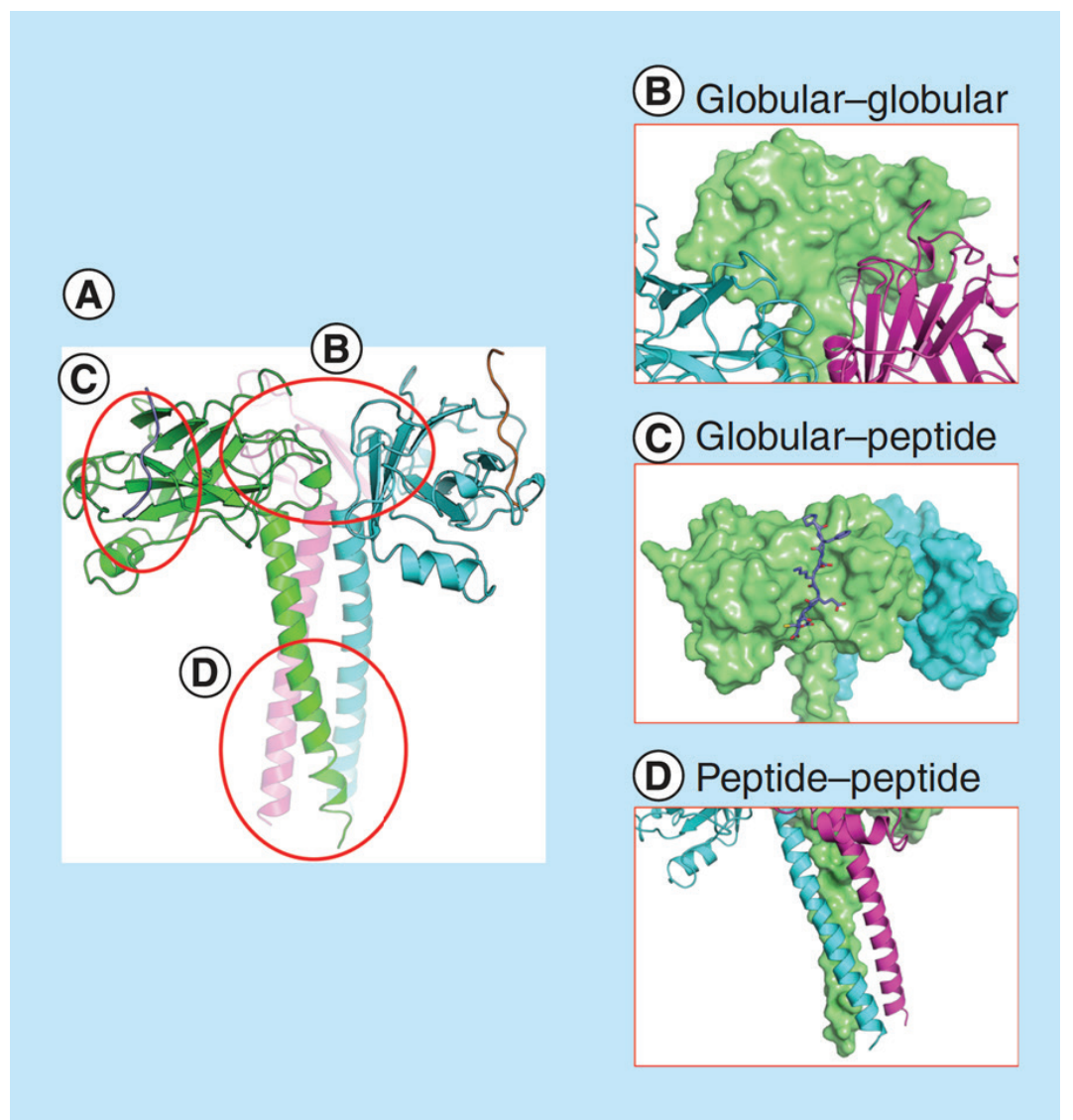

Figure 2. Examples of different types of protein-protein interactions based on protein structure.

(A) Trimeric complex of TRAF2 in complex with peptide (PDB code 1CA9) and molecular surface of PPI derived from different structural classes. (B) Globular protein-globular protein complex. (C) Globular protein with peptide. (D) Peptide with peptide (more details can be found from this review ${ }^{26}$ ).

\section{EXPERIMENTAL \& COMPUTATIONAL METHODS TO IDENTIFY PROTEIN-PROTEIN COMPLEXES}

\section{Experimental methods}

Structural information of protein-protein complexes is fundamental in the rationalized design of PPI modulators which may have potential therapeutic properties. The structural information on the target of interest can be obtained from either experimental or computational methods. The determined protein-protein complexes can assist the designer to reach a better understanding of the required and essential interactions at the atomic level of PPIs and this knowledge can then be utilized to design and develop PPI modulators. 
The structure of protein-protein (or protein-ligand/peptide) complexes, which can be determined by experimental methods at high-resolution, often provides such detailed information to designers, thus identifying the major contributors of the PPI to be inhibited or to be stabilized. Among different experimental methods, $\mathrm{x}$-ray crystallography is a powerful technique that can be employed to solve the $3 \mathrm{D}$ structure of protein-protein complexes. However, distinguishing the true protein-protein interface from artefactual crystal contacts is a significant and nontrivial challenge. ${ }^{42}$ Each partner of the proteinprotein complex appears to form different interfaces with the neighboring molecules in the crystal. ${ }^{42}$ In addition, besides the mentioned crystal contacts, also nonphysiological conditions for crystal formation may result in observation of biologically irrelevant PPIs, which can mislead the PPI modulator design. ${ }^{43}$ Recently, $x$-ray free-electron lasers, the use of which causes diminished radiation damage to the macromolecules of interest, are increasingly used to determine the 3D structure of protein-protein complexes. X-ray freeelectron lasers employs femtosecond $\mathrm{x}$-ray pulses which allows the observation of rapid transitional changes of the structure upon ligand binding. ${ }^{44}$ However, these methods have some limitations especially for using to provide structural insights for complexes which are formed between IDPs. In such cases, circular dichroism and NMR spectroscopy are better suited as they allow the investigation of structural changes that occur upon complex formation. ${ }^{30}$ NMR spectroscopy can be also used to unravel structural properties and key residues for binding of weak PPIs (Kd $>\mathrm{mM}) .{ }^{45}$ Finally, mass spectrometry (MS) offers a great variety of different strategies to investigate the structural properties of proteinprotein complexes ${ }^{46}$, such as by hydrogen-deuterium exchange MS to investigate the PPIs in protein-protein complexes ${ }^{47}$, where surface labeling is readily done with $\mathrm{D} 2 \mathrm{O}$-based buffers. ${ }^{48}$ Surface residues which are accessible to exchange, and thus not involved in complex formation, are labeled with $\mathrm{D} 2 \mathrm{O}$ and will obtain a higher corresponding $\mathrm{m} / \mathrm{z}$ position over time. ${ }^{48} \mathrm{Am} / \mathrm{z}$ position comparison of complex and unbound proteins points out which residues are involved in complex formation. ${ }^{48}$

The latest advances in cryo-EM allow researchers to solve the 3D structure of proteinprotein complexes which have a molecular mass lower than $250 \mathrm{kDa}$ with a resolution from 3 to $5 \AA .{ }^{49,50}$ Cryo-EM is an increasingly popular method for structural studies of large protein complexes. Within the past years, cryo-EM has undergone rapid technological development and became capable of acquiring near-atomic level structures, which makes it suitable for use in drug discovery (besides the established methods of $\mathrm{x}$-ray crystallography and NMR). Cryo-EM allows study of proteins in their near-native (frozen-hydrated) state as well as investigation of larger and more complex systems or samples possessing multiple conformational or compositional states. ${ }^{51,52}$ This may be beneficial, as inhibitor-binding pockets are often flexible in various protein conformations and prediction of hot-spots using computational techniques still remains a challenging task. The cryo-EM technique has been being continuously developed and improved and can now go beyond its earlier 
technical limitations. Breakthroughs came with the determination of 3D structures with resolutions lower than $2 \AA$ and the significant reduction in the lower molecular weight limit for samples that can be studied by cryo-EM have allowed this technique to be applied for various types of proteins, for example, membrane-embedded proteins and protein-ligand complexes. ${ }^{53,54}$ Currently, the cryo-EM technique has increasingly and widely been applied for molecular and structural biology study and was recently used to study PPIs such as the PRMT5-MEP50 complex (molecular weight around $450 \mathrm{kDa}$ ). ${ }^{55}$ The obtained complex structure (resolution at $3.7 \AA$ ) shows several properties and details in agreement and consistent with the previous published $\mathrm{x}$-ray structures (resolutions ranging from 2.1 to $2.9 \AA$ ) further supporting single particle cryo-EM as a high potential technique that can be applied to study human drug discovery targets. ${ }^{55}$ Moreover, cryo-EM can be combined with computational methods, for example molecular dynamics (MD) simulations, to scrutinize molecular mechanisms and interaction networks of complex systems such as has been done for ErmBL-stalled ribosomes with erythromycin (an antibiotic drug), a complex that is being studied in the context of antibiotic drug resistance. Results derived from MD simulations based on the cryo-EM structures provide insight into their fundamental mechanism which can be useful for further drug development. ${ }^{56}$

Despite the suitability of cryo-EM in molecular and structural biology studies, its application in drug discovery, either for lead identification or lead optimization has not been yet reported. ${ }^{40}$ However, as supported by the promising results that are discussed above, and with the current rapid technological improvement of cryo-EM, the method is expected to be applied and considered as a powerful tool in structure-based drug design already in the very near future. ${ }^{40}$ Furthermore, the combination of low-resolution experimental structures derived from cryo-EM and computational techniques like MD simulations as described above can be combined and used for the study of PPIs and for structure-based drug design.

\section{Computational approaches}

However, obtaining atomic level information on PPIs may not always be possible due to inaccessibility to previously mentioned methods while experimental determination of protein-protein complex can in addition be laborious and costly. In such cases, use of in silico methods can help to overcome these limitations for predicting a likely binding mode between two proteins. Protein-protein docking is a versatile tool to study the biologically relevant interactions between two or more proteins-of-interest. Molecular docking programs such as HADDOCK ${ }^{57}$, ICM-Pro ${ }^{58}$, ZDOCK ${ }^{59}$ and $\mathrm{HDOCK}^{60}$ to name just a few can be employed to generate possible binding modes between two proteins. Molecular docking generally provides several possible docking solutions and docking solutions are then often ranked by their corresponding docking score. The top-ranked docking pose is usually selected as the most likely, native-like, structure and used for further 
investigation for PPIs. However, the scoring functions are built to be fast and informative, they do not entirely correlate with biochemical affinity values ${ }^{61}$ and docking scores are often not completely indicative of a most likely biologically relevant structure. Thus, selecting a likely binding pose selection based on scoring functions can be misleading. ${ }^{61}$ This obstacle can be overcome by correct utilization of available biochemical knowledge of the protein-of-interest and/or good use of available structural bioinformatics methods. For example, key residues of a particular PPI derived from NMR spectroscopy ${ }^{62,63}$, or from hydrogen-deuterium exchange MS data ${ }^{64}$ can be exploited in combination with docking solutions to identify a likely binding mode between two proteins. Moreover, essential residues playing important roles in PPIs of an investigated complex can also be obtained from site-directed mutagenesis experiment and the derived information can be used for assisting to build 3D computational models of protein-protein or antibody-antigen complexes. ${ }^{65,66}$ Alternatively, a combination of MD simulations and binding free energy (BFE) calculations (shown in Figure 3), which represents a more accurate approach than simple docking and scoring function, can be used together with experimental data, which can be derived from different methods as mentioned above, to assist designers to distinguish false-positive docking poses from native-like poses. ${ }^{67,68}$ These methods can in addition reveal structural insight into such key residues of the PPIs from identified protein-protein complex and to a certain extent are able to include time-dependent considerations, like flexibility, into the process. ${ }^{34,69} \mathrm{MD}$ simulations on these protein-protein complexes can drive the biomolecular complex to an energetically lower conformation which is more physically and biologically relevant to intermolecular interactions..$^{70} \mathrm{BFE}$ calculation methods can be used to distinguish native-like docking poses from false-positive docking solutions. ${ }^{34,68}$ Several methods for BFE exist, and one such method, molecular mechanics/Poisson-Boltzman (generalized Born) surface area $(\mathrm{MM} / \mathrm{PB}(\mathrm{GB}) \mathrm{SA})^{71}$ is a fast and inexpensive approach as compared with other BFE methods, e.g., free energy perturbation and thermodynamic integration. A likely binding pose should be associated with the lowest BFE, implying a thermodynamically favorable conformation, and should also be the pose of which stays overall stable throughout the length of an MD simulation, allowing only small root mean square deviation fluctuations. BFE decomposition per residue (shown in Figure 3) or in silico alanine scanning are both powerful methods which can exploit the major interacting residues between binding partners. Both of these methods can indicate the type of present interaction and its contribution to the total BFE. Especially in silico alanine scanning can emphasize the effect of sterical and electrostatical changes due to an exchange of the wild-type side chain to an alanine side chain. ${ }^{34,63,71}$

In conclusion, obtaining protein-protein or protein-ligand/peptide complexes, either by computational or experimental methods can allow the identification of residues that are responsible for complex formation (shown in Figure 3). Molecular modelers can harvest 
such data and information, in other words, key residues, secondary structure, length and composition of the protein binding partners, and approximated surface area from the determined complexes to design peptides or peptidomimetics for modulating PPIs as will be discussed in the next section.

\section{Peptides \& peptidomimetics}

Peptides are linear polymers of 2-50 amino acids linked together by amide bonds. In the human body, many peptides such as insulin, oxytocin and cyclosporin are active $\mathrm{e}^{72-74}$ making synthetic and designer peptides attractive molecules for use in drug discovery. Furthermore, in analogy to conventional (small molecule) drugs which often mimic the substrate of an enzyme, peptides could mimic the binding epitope in PPIs, making them attractive molecules in this context. ${ }^{75}$ This often makes the region of the binding partner that is involved in PPI with the target a useful starting point in the development of PPI modulators. Peptides extracted from such binding regions may further be subjected to in silico or in vitro alanine scanning. ${ }^{76}$ This technique involves sequentially changing each residue in a peptide (via synthesis) or in a protein (via site-directed mutagenesis) to alanine. This technique is useful in identifying 'hot-spot' residues, which contribute most to protein-peptide complex formation. ${ }^{77}$ Peptides, however, have several disadvantages, mainly due to their poor bioavailability. Peptides are often large and charged and therefore poorly or not at all absorbed following oral application. Once in the bloodstream, they are rapidly degraded by peptidases and are rapidly cleared from the body. ${ }^{78}$ Furthermore, the large flexibility of peptides implies that there is an entropy penalty upon folding and binding. However, if a certain peptide has unwanted properties for a given application, it can still function as a starting point for the development of peptidomimetics. These are molecules that mimic the structure and function of a certain peptide, but do not have their inherent disadvantages. ${ }^{79}$ Peptidomimetics are historically divided into three classes. ${ }^{80}$ Type I are the backbone mimetics. Type II peptidomimetics are the functional mimetics, which are nonpeptidic molecules that have a similar function to the parent peptide, but are not structurally related. Type III are the topological mimetics, which are molecules with a nonpeptidic scaffold, but which make the same interactions.

\section{In silico techniques for the discovery \& design of therapeutic peptides}

Many steps for identifying and optimizing therapeutic peptides or peptidomimetics are amenable to in silico techniques. Like with small molecules, peptide-based drug discovery can be divided to ligand- and target-based approaches. Ligand-based techniques include multiple sequence alignments of known binding peptides or PPI epitopes to derive information about interacting amino acids. Generation and scoring of peptide conformations into a binding pocket of target proteins can be done using MD simulations or protein-peptide docking tools. ${ }^{81}$ Target-based approaches can generally be divided into three stages: binding site detection, docking and affinity prediction. In the context of 


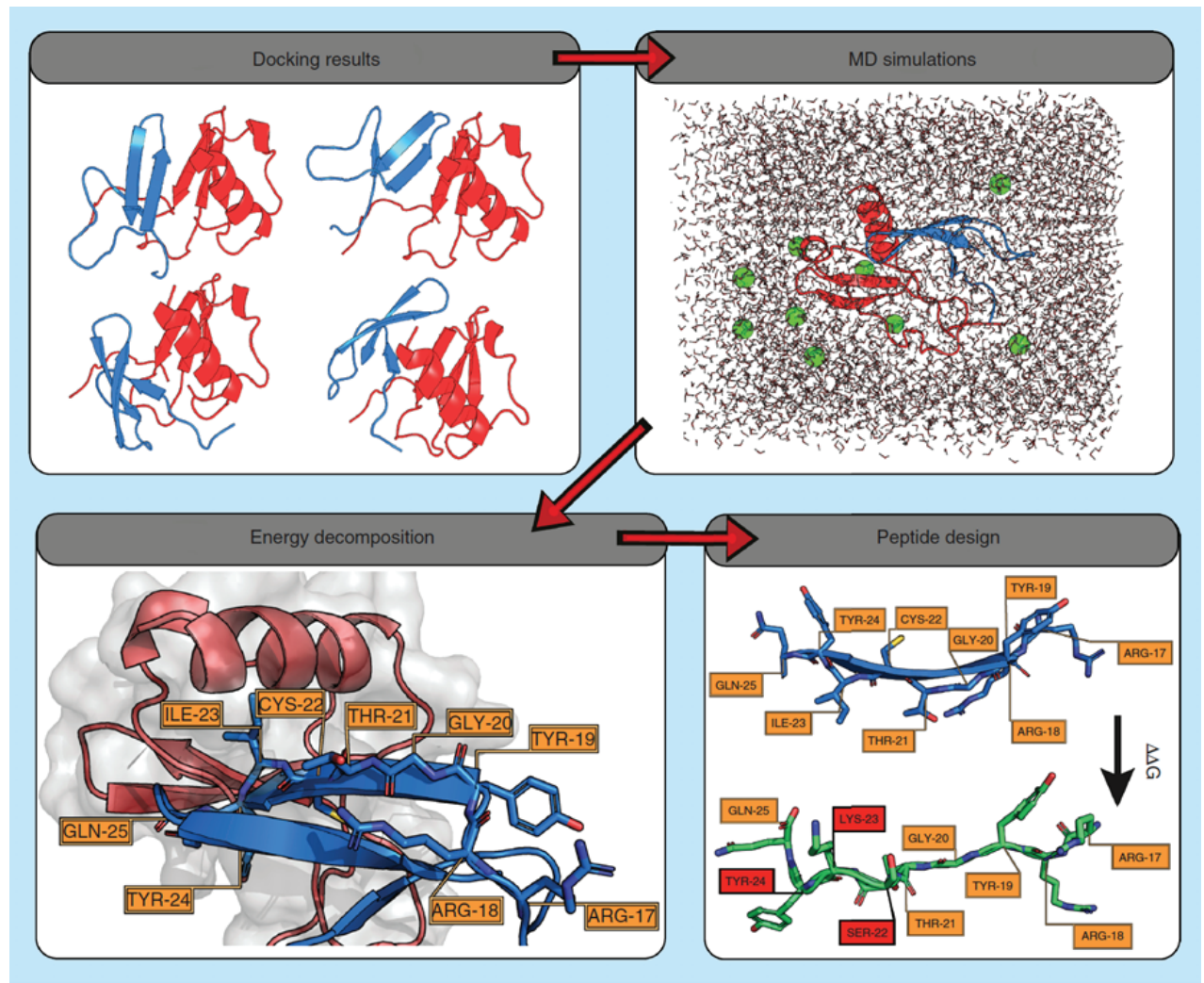

Figure 3. Schematic representation of generic approach to identify a likely binding mode of proteinprotein complex which is then served as a starting structure for inhibitor design. Protein-protein docking generates several decoys along with the likely native structure during the exploration of the PPIs space. Molecular dynamics simulations can further investigate the likelihood of each docking result to form the complex-of-interest by further shifting the structures to relatively lower energy landscapes. Use of energy decomposition per residue from BFE calculations points out the PPIs at residue level and provides required information for the design of peptides. BFE of designed peptides can be further improved by introducing single point mutation which may lower the BFE to perform better inhibition or stabilization.

BFE: Binding free energy; MD: Molecular dynamics; PPI: Protein-protein interaction.

PPIs, the binding site is often determined by the binding interface between two proteins which can be identified by use of various experimental or computational methods as discussed in the previous section. In addition, several databases of protein-peptide interactions or several online tools can be used to search for binding hotspots between protein and peptides (more details can be found in this review ${ }^{81}$ ). The second step involves finding a likely binding pose for the peptide onto the protein. Peptide-protein docking methods can be used for this purpose. These methods can be divided in three classes, namely template-based methods, local- and global-docking methods ${ }^{82}$ In template-based docking, a known complex is provided to the docking program. Based on this template, 
the program attempts to find a likely binding mode for the complex under investigation. ${ }^{82}$ In local docking, the user specifies the binding site and the program attempts to dock a peptide at the specified location on the surface of a target structure. Various specialized programs for protein-peptide (or protein) docking exist for this objective as described above, and also small-molecule molecular docking programs, for example, AutoDock Vina $^{83}$, Gold ${ }^{84}$, Glide ${ }^{85}$ and Surflex-Dock ${ }^{86}$ have been used for this purpose. Although these programs have some success for peptides of up to three amino acids, they are not suitable for longer chains. ${ }^{82}$ In global docking, no information about the binding site is provided a priori. Thus, the docking programs use different algorithms to investigate suitable binding spots and consequently attempt to dock peptides onto those identified binding spots. ${ }^{82}$ There are two approaches for affinity prediction: sequence-based and structure-based prediction. In sequence-based affinity prediction, the amino acids are converted to abstract amino acid property descriptors after which machine learning is used to estimate activity ${ }^{87}$ In the structural approach, the 3D structure of the protein-peptide complex is used. Various techniques are used to estimate binding affinity, such as combined quantum mechanics/molecular mechanics, semi-empirical Poisson-Boltzmann/surface area, and empirical conformational free energy analysis. ${ }^{88}$ Although, these methods can be time consuming, which may limit their use in screening applications, these methods can be applied in subsequent optimization steps to predict binding affinity of optimized or designed peptidic compounds. Several research groups including ours have successfully applied BFE such as MM/PBSA or MM/GBSA to estimate binding affinity of designed peptides which can significantly reduce the amount of peptides that will be synthesized and tested experimentally. ${ }^{34,89-91}$

\section{From peptides to peptidomimetics}

Once a functional peptide has been discovered that has the capacity to modulate a given PPI, such a peptide may provide a structural basis for the design of a peptidomimetic. Use of peptidomimetics can then offer the advantages of the peptide modulator but it has less of the known disadvantages that were discussed above for use of peptides. Many strategies exist for deriving peptidomimetics from peptides, and an example of this is illustrated in Figure 4 and 5. Type I peptidomimetics can be derived by gradually changing a bioactive peptide. The least drastic change to the original peptide is the inclusion of nonnatural amino acids ${ }^{92}$ into the peptide sequence. Slightly more invasive is the cyclization of the linear peptide, which makes the peptide more rigid and thereby often less prone to degradation..$^{93-95}$ One strategy for cyclization is the linking of two amino acids. ${ }^{75,96-98}$ This method can be used to induce secondary structure and to provide more rigidity for the peptide. The prime example of this approach is stapling of peptides to stabilize their $\alpha$-helical form (see an example in Figure 5). ${ }^{99}$ The introduction of rigidity or reduction in flexibility can have a positive effect on the thermodynamics (i.e., entropy) of binding of the ligand to its binding partner. Retro-inverso peptides refer to the use of $\mathrm{D}$-amino 
acids instead of the naturally used L-amino acids. The sequence of the original peptide is then reversed to orient the residues in the same way as for the L-amino acid peptide. Retro-inversion often improves stability, since proteases are less prone to recognize the D-amino acids. ${ }^{100}$ Peptoids refer to peptidomimetics in which the amino acid side chains are attached to the amide nitrogen instead of the $\alpha$ carbon. ${ }^{101,102}$ In peptoids, the sequence is also reversed to keep the residues in the same orientation with respect to the backbone carbonyls. Peptoids have no backbone stereo centers and are more flexible than peptides. Finally, small molecules might be identified that capture the pharmacophoric and functional features of a parent peptide.

In addition to the rational design and modification of peptides into stable peptidomimetic as discussed above, various in silico strategies exist for the design and discovery of peptidomimetics. These techniques are especially useful for the discovery of type II and type III peptidomimetics. De novo approaches use a nonpeptide template for fitting fragments into the binding site of the target protein and then attempt to connect these fragments together. ${ }^{103}$ In a sequence-based approach, features of small molecules are mapped onto amino acids, allowing them to be screened against a peptide target. ${ }^{104}$ Pharmacophoric approaches, either peptide-based or receptor-based, can also be employed to search for novel peptidomimetics. ${ }^{104}$ In the receptor-based approach, pharmacophore features are generated based on the target structure, whereas peptide structures or any available peptide-protein complexes may be utilized to generate pharmacophore models for the peptide-based approach. A last example of in silico methods used for the design and development of peptidomimetics are geometry-based approaches which attempt to discover molecules that have similar geometric features as the parent peptide. ${ }^{104}$ In addition, a combination of the pharmacophoric and geometric methods can also be used to screen for peptidomimetics. ${ }^{105}$

\section{From protein-protein/peptide complex 3D structures to novel modulators of PPIs}

The drug discovery and development process is a time consuming process that generally requires a high financial investment. Rapid in silico methods like molecular docking or combinations of short MD simulations with BFE calculations (which require less computational time and cost) can, however, significantly accelerate the drug design process and reduce the cost of the overall drug discovery. These approaches can be applied at different steps, for example, in the identification of a 3D structure of a protein-protein complex step and/or for design of modulators (inhibitors or stabilizers) for PPIs. Here, we present examples where the availability of 3D structures of protein-protein/peptide complexes and in silico methods play a significant role in the development of modulators for PPIs. 


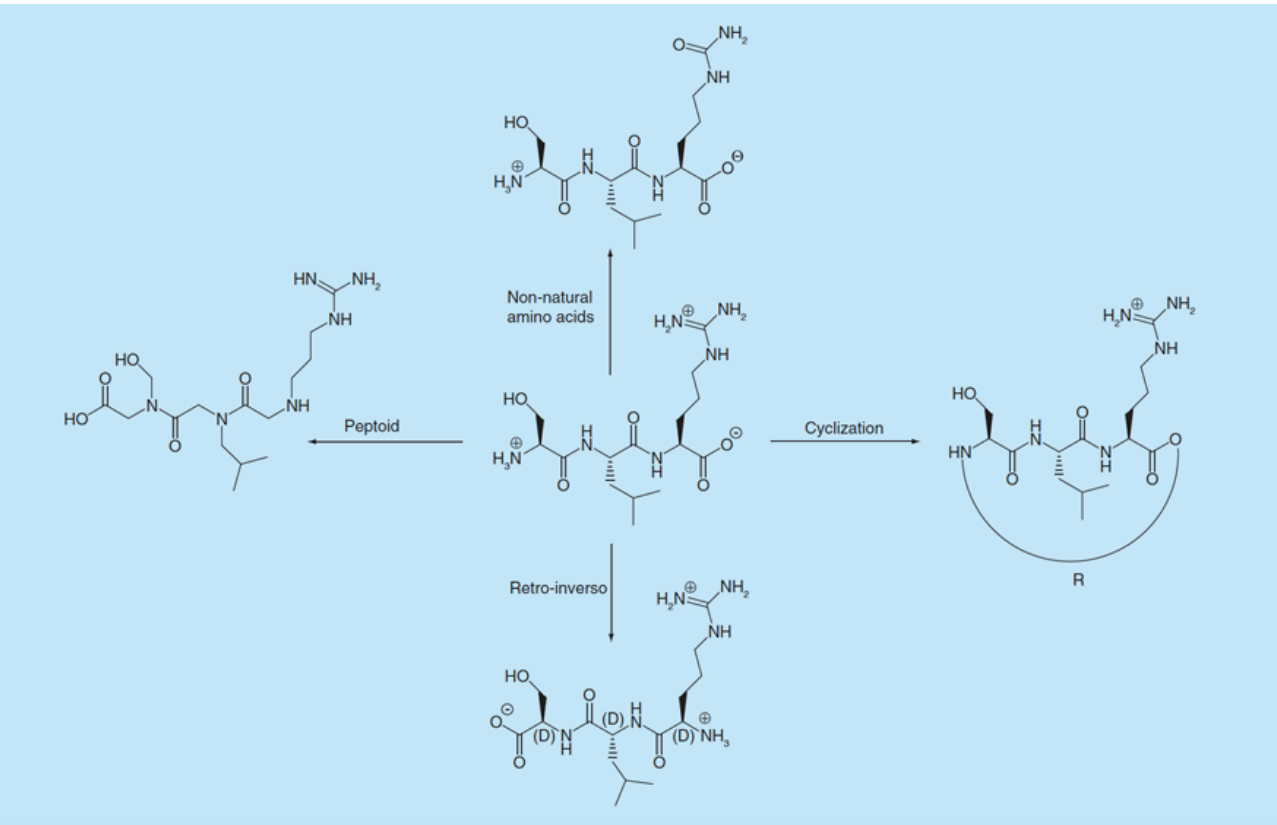

Figure 4. Examples of strategies to convert proteinogenic natural amino acid peptides into peptidomimetics.

\section{Targeting globular proteins}

PPI inhibitors: iPPIs

\section{Cancer therapy}

Tumor suppressor $\mathrm{p} 53$ plays a crucial role in protection from tumor development. During carcinogenesis, p53 is negatively regulated by MDM2 overexpression which results in a loss of its function. ${ }^{106}$ The $\mathrm{x}$-ray structure of the $\mathrm{p} 53-\mathrm{MDM} 2$ complex (PDB code 1YCR) reveals that $\mathrm{p} 53-\mathrm{MDM} 2$ interactions are mediated by a 15 -residue $\alpha$-helical domain of p53 that includes three amino acid residues (Phe19, Trp23 and Leu26) on p53 that are critical for MDM2 binding. ${ }^{107}$ This knowledge allows for the design of inhibitors to interrupt p53-MDM2 interactions, which became an attractive approach in the development of cancer treatments based on reactivation of $\mathrm{p} 53$. Although most of the p53-MDM2 inhibitor design strategies utilize alternative approaches ${ }^{108}$, simple peptidomimetics and peptide-derived compounds are recently becoming popular. For example, the $\alpha$-helical transactivation domain of $\mathrm{p} 53$ was used to provide a starting peptide from which optimized peptides could be derived. Peptidic inhibitors should retain its $\alpha$-helical structure and preserve the key residues for interaction with MDM2 (as displayed in Figure 5). Therefore, the concept of 'peptide stapling', is applied to this $\alpha$-helical stretch of p53 by linking side chain of two non-natural amino acid residues together in order to keep $\alpha$-helical conformation of the peptide as shown in Figure 5. By doing this, stabilized $\alpha$-helix of p53 (SAH-p53) peptides were designed and optimized by stapling the $\mathrm{p} 53_{14-29}$ sequence at different positions. The most potent peptide exhibits 
high binding affinity with an improved cellular permeability property that is better than that of the unmodified p53 peptide and also exhibits a dose-dependent inhibition of osteosarcoma cell (SJSA-1) viability $\left(\mathrm{EC}_{50}=8.8 \mu \mathrm{M}\right) .{ }^{99}$ Moreover, the structure of the $\alpha$-helix of $\mathrm{p} 53$ can also be utilized to identify small compounds to interrupt p53-MDM2 interactions (as shown in Figure 5). For instance, Ding et al. ${ }^{109}$ have searched for chemical moieties that can mimic the indole ring, a side chain of Trp23 which is a key residue for interacting with MDM2. The oxindole ring which can perfectly mimic the side chain of Trp was identified and applied for substructure search for compounds containing the oxindole ring. Subsequent molecular docking was employed to investigate the binding between the identified compounds and also to assist in the modification and optimization of small-molecule inhibitors of the p53-MDM2 complex. By doing so, a potent smallmolecule inhibitor was developed that can inhibit the interaction with an associated $\mathrm{K}_{\mathrm{i}}$ value of $86 \mathrm{nM}$. These studies are excellent examples to demonstrate that protein-protein complexes and structure-based approaches can be exploited to design and develop highly potent inhibitors (either peptides or small compounds) to interrupt PPIs.

Another example of a protein family widely studied in the context of PPI modulator development is the $\mathrm{Bcl}-2$ protein family which has important roles in regulation of programmed cell death. Also here represents a good example for which the novel PPI modulators are designed and developed based on available 3D structures of protein-protein complexes. ${ }^{110,111}$ The Bcl-2 family consists of pro-apoptotic and anti-apoptotic proteins that interact with each other to form heterodimers. Anti-apoptotic proteins of the $\mathrm{Bcl}-2$ family, which are $\mathrm{Bcl}-2, \mathrm{Bcl}-\mathrm{XL}, \mathrm{Mcl}-1, \mathrm{Bcl}-\mathrm{B}, \mathrm{Bcl}-\mathrm{w}$ and $\mathrm{A} 1 / \mathrm{Bfl} 1$, are overexpressed and often altered in tumor cells. Thus these proteins represent potential targets for cancer therapy. The hydrophobic groove of these anti-apoptotic proteins binds to the $\mathrm{BH} 3$ domain consisting of a 15-amino acid conserved sequence. ${ }^{12}$ This information and the availability of $\mathrm{BH} 3$ domains-anti-apoptotic protein complexes are a good starting point and can be used for designing small compounds or peptides mimicking $\mathrm{BH} 3$ domain based on interactions between the $\mathrm{BH} 3$ domain and anti-apoptotic proteins. Some of these newly developed molecules have now entered clinical trials as shown in Table 1.

\section{Therapy of inflammatory disorders}

Inflammatory responses are regulated by different pathways such as via interactions between chemokines and their specific receptors, for example, CXCL8-CXCR1 interactions ${ }^{89}$ or through a recently discovered mechanism via ligation of a CCL5-HNP1 heterodimeric complex with CCR5.$^{35}$ These two cases are excellent examples where in silico methods can play important roles for the study of PPIs and the possible translation of the structural knowledge to design peptidic inhibitors. To experimentally determine the 3D structure of a CXCL8-CXCR1 complex either by $\mathrm{x}$-ray crystallography or cryo-EM is laborious, and at present no $\mathrm{x}$-ray complex structures of the CCL5-HNP1 complex are available in the 


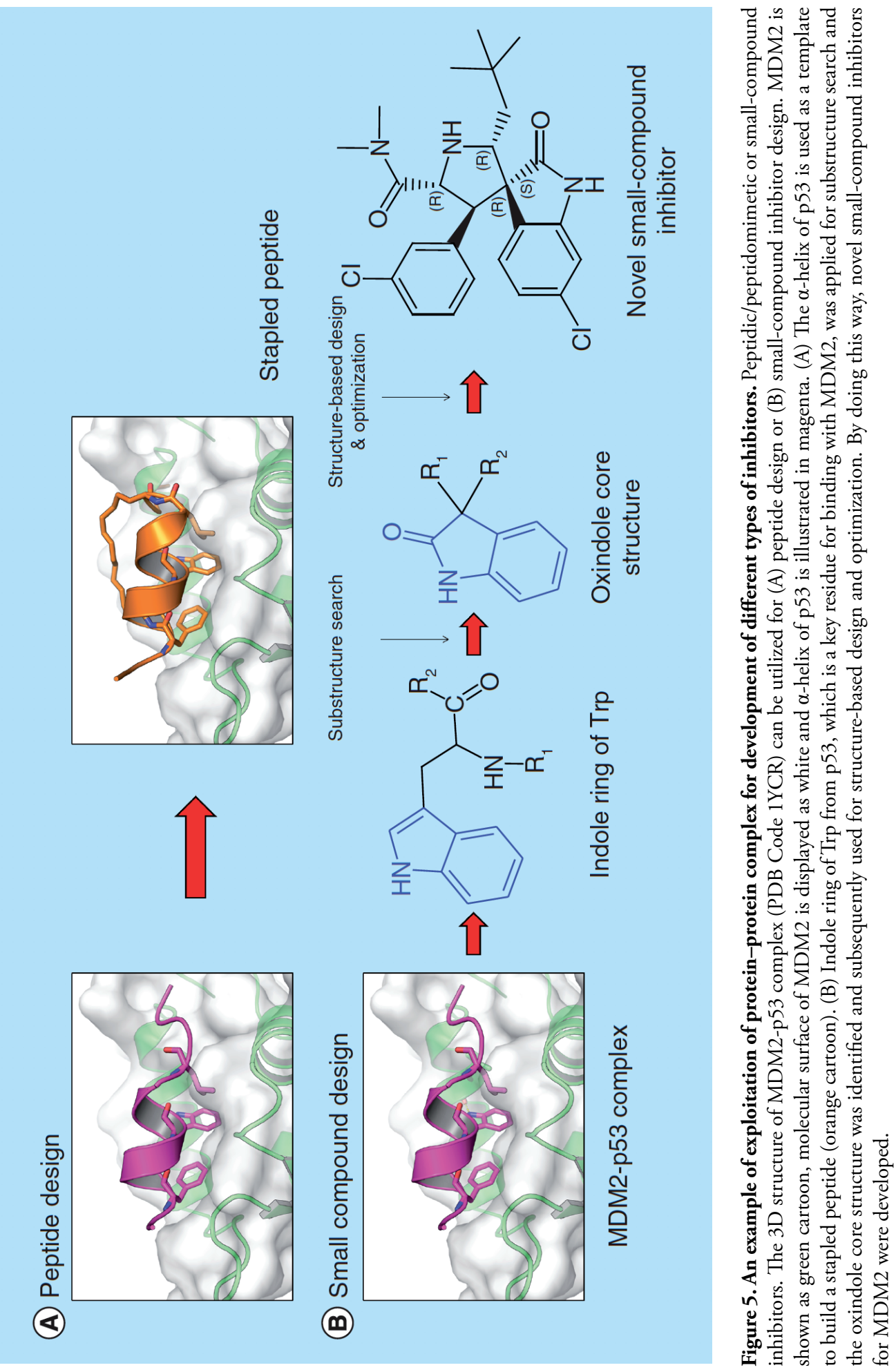


Table 1. Example of small compounds or peptides targeting different protein targets in the Bcl-2 protein family.

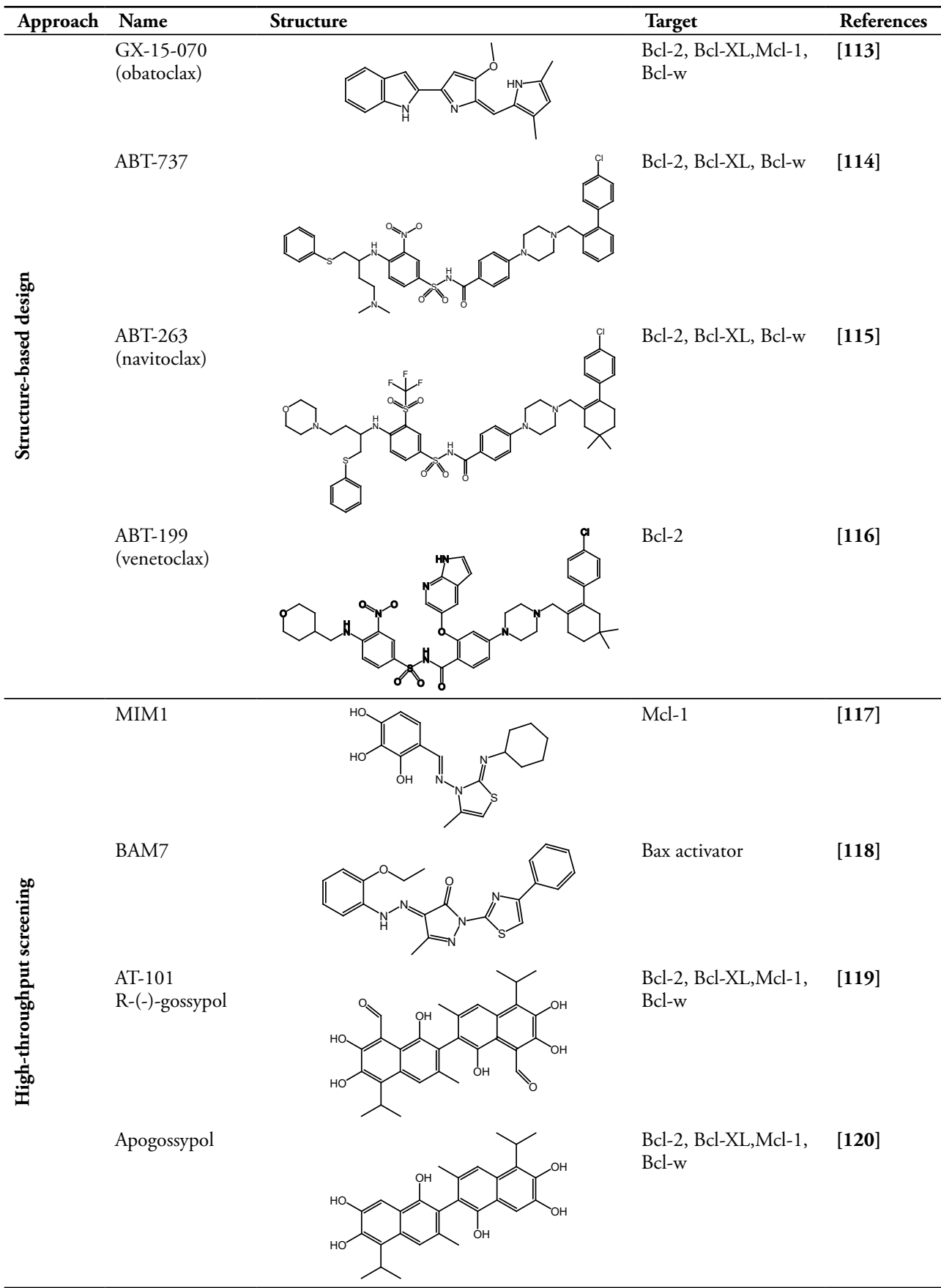

These inhibitors were identified and developed by using different approaches, for example, structure-based design by mimicking interactions between the $\mathrm{BH} 3$ domain and anti-apoptotic proteins or high-throughput screening method. 
Protein Data Bank. ${ }^{121}$ Therefore, alternative fast and inexpensive in silico approaches (i.e., combination of molecular docking, MD simulations and BFE calculations) were utilized to identify a likely binding mode of the CXCL8-CXCR1 ${ }^{89,122}$ and of the CCL5-HNP1 complex. ${ }^{34}$ Subsequently, the identified complexes were exploited to design peptides that can interrupt CXCL8-CXCR1 and CCL5-HNP1 interactions. For example, from the derived CXCL8-CXCR1 complex several peptides were designed based on the N-loop of CXCL8 which is the main part that interacts with the $\mathrm{N}$-terminus of CXCR1. The most potent peptidic inhibitor binds to the CXCR1-derived peptide exhibiting $\mathrm{K}_{\mathrm{D}}$ at micromolar level $(252 \mu \mathrm{M})$ and this derived peptide also shows additionally activity in vivo by inhibiting monocyte adhesion and transmigration. ${ }^{89}$ Likewise, a series of peptides based on the HNP1 sequence that bind to CCL5 was rationally designed and the binding affinity of individual peptides to CCL5 was in silico predicted. ${ }^{34}$ By doing this way, only ten peptides from more than a billion possible candidate peptides were selected and synthesized and in vitro tested. The most potent inhibitor called 'SKY peptide' was chosen and then tested for its inhibitory activity in vivo and a mouse model of myocardial infarction. Results reveal that inhibition of CCL5-HNP1 interactions by 'SKY' peptide can inhibit monocyte adhesion and reduce myocardial macrophage accumulation. ${ }^{35}$ These studies demonstrate that in silico methods can be efficiently used to determine protein-protein complexes and rationally design inhibitors that have a potential for further development as anti-inflammation drugs. Furthermore, a combination of NMR study, MD simulations and BFE calculations can be utilized to identify a heterodimeric complex of different chemokine pairs, for example, CCL5-CXCL4, CCL5-CCL17 and CCL5-CXCL12 heterodimer. The derived complexes provide structural information such as on the type of interactions. Also these complexes can be analyzed via computational methods to identify key interacting residues at the interface that can be exploited to design stable and specific peptidic inhibitors to prevent complex formation of chemokine heterodimeric pairs. These inhibitory peptides are active not only in vitro, but they also show inhibitory activity in different animal models of inflammatory diseases. ${ }^{33,123}$

\section{PPI stabilizers: sPPIs}

Some of the most extensively studied proteins for the development of PPI stabilizers are the 14-3-3 proteins which are a family of conserved regulatory molecules that can bind to different partners and are involved in many cellular functions such as apoptosis, cell cycle regulation and signal transduction. ${ }^{124}$ Fortunately, x-ray structures of the 14-3-3 proteins in complex with different binding partners are available from the Protein Data Bank allowing molecular modelers to use these structures for rational design of selective stabilizers for different protein-protein complexes. ${ }^{22,125,126}$ For instance, recently, MD simulations were applied to investigate the interaction networks of human 14-3-3 sigma in complex with TASK-3 peptide and the stabilizer Fusicoccin A (PDB code 3P1O). The derived results from the MD simulations provide insight into key interactions of 
the complex which were then utilized to rationally design PPI stabilizers. As suggested by MD simulations, the novel PPI stabilizers which show additional interactions with the identified key residues exhibit significantly improved potency. ${ }^{127}$ This study clearly demonstrates the robustness of the combination of 3D structures and in silico approaches for the rational design of PPI modulators.

Human calcium-activated $\mathrm{K}^{+}$channels (KCa) of the small- (SK) and intermediateconductance (IK) $\mathrm{K}^{+}$channel types are reported to be involved in several diseases, such as cancer, autoimmune disorders, neurodegenerative disease and vascular inflammation. ${ }^{28}$ Similar to the work on 14-3-3 mentioned above, the availability of $x$-ray structures of SK2 (calcium-activated $\mathrm{K}^{+}$channel 2) with $\mathrm{Ca}^{+}$-bound calmodulin $(\mathrm{CaM})$ and the stabilizers (1-EBIO and PHU) were applied for the development of novel stabilizers (NS309, CyPPA and DCEBIO). Due to the poor solubility of NS309 and CyPPA and the difficulty to co-crystallize a complex with these compounds bound to it, researchers were inspired to perform molecular docking and MD simulations instead to examine the binding of these compounds with the SK2-CaM complexes. ${ }^{129}$ The derived results were utilized for further development of stabilizers with improved binding affinity and selectivity. This shows that in such cases where co-crystallization of protein complexes has some limitations, in silico methods can provide an alternative for rational modulator design and protein-protein-ligand interaction study.

\section{Targeting IDPs/IDPRs to interrupt PPIs}

A major challenge in targeting IDPs and IDPRs is the limitation of experimental and computational methods used to completely characterize the heterogeneous conformations and to identify transient druggable pockets or binding sites of IDPs/IDPRs and how to exploit these structures through drug discovery. ${ }^{130}$ However, computational methods such as different enhanced MD simulations techniques or coarse-grained simulations can be used to investigate dynamic motions, flexibility, secondary structures and transient pockets of IDPs/IDPRs. ${ }^{131-135}$ One of the most studied disordered PPIs and promising cancer drug targets is the c-Myc-Max complex. ${ }^{136-139}$ In their monomer conformation, both c-Myc and Max are IDPs but upon complex formation they fold into a secondary structure to form a stable heterodimer. Two different strategies can be utilized to develop inhibitors for the disruption of c-Myc-Max interactions (as displayed in Figure 6). The first approach is called 'Trap mode' in which the unfolded c-Myc conformation is used as a target to search for compounds that can bind this nonfunctional conformation and that prevents it from binding with the Max protein ${ }^{140}$ (as shown in Figure 6). Jin et al. ${ }^{15}$ and Yu et al. ${ }^{16}$ have applied replica exchange MD simulations to examine the folding and conformational changes of the $\mathrm{c}-\mathrm{Myc}_{370-400}$ peptide and have used different conformations extracted from replica exchange MD for virtual screening. They have identified novel small compounds binding the $\mathrm{c}-\mathrm{Myc}_{370-409}$ peptide that show inhibitory activity at the 


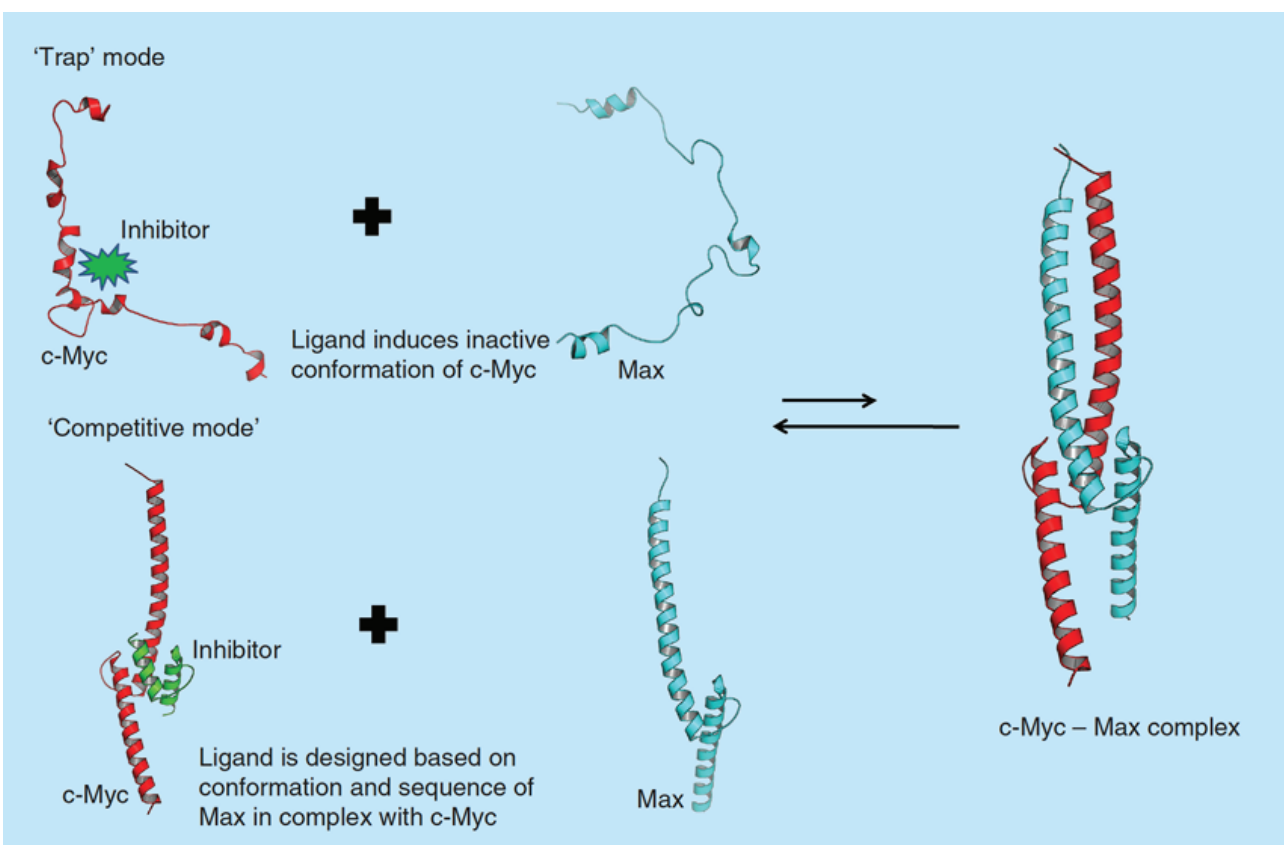

Figure 6. Different approaches for development of inhbitors to prevent C-Myc-Max complex formation. The 'Trap mode', inhibitors were developed to bind the unfolded conformation of C-Myc protein whereas the 'Competitive mode', inhibitors were designed to compete the binding of Max protein with the folded confomation of C-Myc protein. ${ }^{140,147}$

micromolar level in in vitro assays that also inhibiting the growth of c-Myc-overexpressing cells. ${ }^{16}$ Another strategy to develop modulators to interrupt c-Myc-Max interactions is called 'Competitive mode' and with this strategy the stable dimeric c-Myc-Max complex is utilized to rationally design compounds to inhibit c-Myc-Max interactions (as also shown in Figure 6). Since experimental 3D structures of c-Myc-Max complexes are available from the PDB, this approach has more advantages and it is theoretically easier since the inhibitor design is based on the properties and interactions of the complex. Different types of inhibitors, for instance stapled Max-derived peptides, peptidomimetics, a mutant of the C-terminal region of MYC (termed OMOMYC) ${ }^{141,142}$ are developed and designed based on the c-Myc-Max complex. ${ }^{140,143}$ Several clinically relevant disordered proteins such as A $\beta$, EWS-Fli1, STAT3, HIF- 1 and $\beta$-catenin are currently being targeted for development of new drugs and extensive computational methods can be applied to investigate binding pocket and protein conformations or to screen for novel inhibitors. ${ }^{140,144-146}$ 


\section{CONCLUSION}

During the last 20 years, there has been a rapid growth in the amounts of modulators (inhibitors or stabilizers) that are able to target PPIs. This development is a clear indication that PPIs are claiming their position in drug discovery and development research. The realization that such flat surfaces at the PPI interface and unstructured parts of IDPs/IDPRs can be targeted by peptides or small compounds has sparked increasing interests by drug researchers and modelers to explore these structures, which used to be considered as not druggable. Certainly, currently prescribed drugs are not limited to only small compounds. Several peptides have already been approved by the responsible authorities or are now entering the clinical stages of development. ${ }^{74,78}$ Furthermore, peptides can be utilized as a starting structure to develop peptidomimetics or small compounds with improved solubility and cell permeability properties. Therefore, modulations of PPIs by peptides represent a trend that receives rapidly increasing interest from the drug discovery research field. Targeting the unstructured parts of IDPs/IDPRs which are involved in PPIs is now becoming another trend in the research field of drug discovery and development. This trend is fueled by smart use of several technologies, for example, circular dichroism- or NMR-spectroscopy or in silico methods such as MD simulations that can be applied to investigate protein secondary structure and presence of transient binding pockets for the IDPs/IDPRs studied. These additional data can be utilized for development of inhibitors.

Several studies as discussed here have shown that the identified protein-protein complexes either from experimental or computational approaches can be used to design inhibitors or stabilizers to modulate PPIs. Moreover, several PPI modulators are now entering the clinical stages. Therefore, these are clear evidences to prove that PPIs represent promising drug targets and protein-protein complexes can be useful for using as starting structures to design peptides, peptidomimetic or small compounds to modulate PPIs.

\section{FUTURE PERSPECTIVE}

Determination of 3D structures of target protein-protein complexes is the key step to success in structure-based molecular design for PPIs. Experimental methods (e.g., x-ray crystallography and NMR spectroscopy) and computational methods (e.g., molecular docking and MD simulations) can be used for this purpose. The high performance of computers and MD simulation packages nowadays enable us to perform simulations on specialized processors, GPUs, which can significantly speed up and accelerate calculations. ${ }^{148,149}$ Therefore, MD simulations can now be routinely employed to investigate protein dynamic motions, conformational changes and detailed atomistic interactions at the interface of protein-protein complexes and also to identify the presence of transient 
druggable pockets in IDPs/IDPRs. This derived information can be exploited to rationally design PPI modulators. Moreover, fast and accurate BFE methods have been applied to predict binding affinity of compounds and several studies have demonstrated that this approach can be applied for this purpose. Thus, BFE methods can be used to (relatively) estimate binding affinities for prioritizing compounds prior to their synthesis and experimental testing of their biological activity. Taken together, computational methods represent a powerful tool that can be applied together with experimental methods for the study of PPIs and for molecular design applications. These in silico methods are now increasingly used in medicinal and pharmaceutical chemistry research to guide and support experimentalists.

Cryo-EM technology is currently rapidly emerging in the biomedical research field and it has been applied to study the molecular structure of different protein classes. Even though the application of this method in structure-based drug design has not yet been well described and widely used, the groundbreaking determination of 3D structures of low-molecular-weight therapeutic proteins with high resolutions by means of cryoEM technique is indicative of the clear promise this technique holds for application in structure-based molecular design in the near future. Not only high resolution cryo-EM structures, but also low resolutions cryo-EM structures can serve as a basis to perform extensive MD simulations, so as to study structural and dynamic properties of proteins and to investigate PPIs. For such cases in which determination of 3D structures of complexes either by $\mathrm{x}$-ray crystallography or cryo-EM technique is difficult to achieve, NMR or mass spectrometry can also alternatively be employed to scrutinize key residues for PPIs. The derived results can be combined with in silico approaches to determine 3D complexes as described above.

\section{FINANCIAL \& COMPETING INTERESTS DISCLOSURE}

This work has received funding from the Horizon 2020 Framework Program for Research and Innovation of the European Union under grant agreement no 675746 (J Hrdinova, B Ercig, GAF Nicolaes) and from the European Research Council (ERC Consolidator grant to E Lutgens, grant no. 681483). X Liu has received funding from the China Scholarship Council. The authors have no other relevant affiliations or financial involvement with any organization or entity with a financial interest in or financial conflict with the subject matter or materials discussed in the manuscript apart from those disclosed.

No writing assistance was utilized in the production of this manuscript. 


\section{REFERENCES}

1. Braun P, Gingras AC. History of protein-protein interactions: from egg-white to complex networks. Proteomics 12(10), 1478-1498 (2012).

2. Petta I, Lievens S, Libert C, Tavernier J, De Bosscher K. Modulation of protein-protein interactions for the development of novel therapeutics. Mol. Ther. 24(4), 707-718 (2016).

3. Ryan DP, Matthews JM. Protein-protein interactions in human disease. Curr. Opin. Struct. Biol. 15(4), 441-446 (2005).

4. Bosch J. PPI inhibitor and stabilizer development in human diseases. Drug Discov. Today Technol. 24, 3-9 (2017).

5. Ercig B, Wichapong K, Reutelingsperger CPM, Vanhoorelbeke K, Voorberg J, Nicolaes GAF. Insights into 3D Structure of ADAMTS13: a stepping stone towards novel therapeutic treatment of thrombotic thrombocytopenic purpura. Thromb. Haemost. 118(1), 28-41 (2018).

6. Villoutreix BO, Miteva MA. Discoidin domains as emerging therapeutic targets. Trends Pharmacol. Sci. 37(8), 641-659 (2016).

7. Arkin MR, Tang Y, Wells JA. Small-molecule inhibitors of protein-protein interactions: progressing toward the reality. Chem. Biol. 21(9), 1102-1114 (2014).

8. Fuller JC, Burgoyne NJ, Jackson RM. Predicting druggable binding sites at the protein-protein interface. Drug Discov. Today 14(3-4), 155-161 (2009).

9. Rognan D. Rational design of protein-protein interaction inhibitors. Med. Chem. Comm. 6(1), 51-60 (2015).

10. Arkin MR, Wells JA. Small-molecule inhibitors of protein-protein interactions: progressing towards the dream. Nat. Rev. Drug Discov. 3(4), 301-317 (2004).

11. Labbe CM, Kuenemann MA, Zarzycka B et al. iPPI-DB: an online database of modulators of proteinprotein interactions. Nucleic Acids Res. 44(D1), D542-D547 (2016).

12. Wojcik P, Berlicki L. Peptide-based inhibitors of protein-protein interactions. Bioorg. Med. Chem. Lett. 26(3), 707-713 (2016).

13. Kuenemann MA, Sperandio O, Labbe CM, Lagorce D, Miteva MA, Villoutreix BO. In silico design of low molecular weight protein-protein interaction inhibitors: overall concept and recent advances. Prog. Biophys. Mol. Biol. 119(1), 20-32 (2015).

14. Stumpf MP, Thorne T, De Silva E et al. Estimating the size of the human interactome. Proc. Natl Acad. Sci. USA 105(19), 6959-6964 (2008).

15. Jin F, Yu C, Lai L, Liu Z. Ligand clouds around protein clouds: a scenario of ligand binding with intrinsically disordered proteins. PLoS Comput. Biol. 9(10), e1003249 (2013).

16. Yu C, Niu X, Jin F, Liu Z, Jin C, Lai L. Structure-based inhibitor design for the intrinsically disordered protein c-Myc. Sci.Rep. 6, 22298 (2016).

17. Kukar TL, Ladd TB, Bann MA et al. Substrate-targeting gamma-secretase modulators. Nature 453(7197), 925-929 (2008). 


\section{Chapter 4}

18. Wildhagen KC, Garcia De Frutos P, Reutelingsperger CP et al. Nonanticoagulant heparin prevents histone-mediated cytotoxicity in vitro and improves survival in sepsis. Blood 123(7), 1098-1101 (2014).

19. Krishnan N, Koveal D, Miller DH et al. Targeting the disordered C terminus of PTP1B with an allosteric inhibitor. Nat. Chem. Biol. 10(7), 558-566 (2014).

20. Lantz KA, Hart SG, Planey SL et al. Inhibition of PTP1B by trodusquemine (MSI-1436) causes fatspecific weight loss in diet-induced obese mice. Obesity (Silver Spring) 18(8), 1516-1523 (2010).

21. Milroy LG, Bartel M, Henen MA et al. Stabilizer-guided inhibition of protein-protein interactions. Angew. Chem. Int. Ed. Engl. 54(52), 15720-15724 (2015).

22. Zarzycka B, Kuenemann MA, Miteva MA, Nicolaes GAF, Vriend G, Sperandio O. Stabilization of protein-protein interaction complexes through small molecules. Drug Discov. Today 21(1), 48-57 (2016).

23. Fischer G, Rossmann M, Hyvonen M. Alternative modulation of protein-protein interactions by small molecules. Curr. Opin. Biotechnol. 35, 78-85 (2015).

24. Modell AE, Blosser SL, Arora PS. Systematic targeting of protein-protein interactions. Trends Pharmacol. Sci. 37(8), 702-713 (2016).

25. Wang N, Lodge JM, Fierke CA, Mapp AK. Dissecting allosteric effects of activator-coactivator complexes using a covalent small molecule ligand. Proc. Natl Acad. Sci. USA 111(33), 12061-12066 (2014).

26. Scott DE, Bayly AR, Abell C, Skidmore J. Small molecules, big targets: drug discovery faces the protein-protein interaction challenge. Nat. Rev. Drug Discov. 15(8), 533-550 (2016).

27. Miller $S$. The structure of interfaces between subunits of dimeric and tetrameric proteins. Protein. Eng. 3(2), 77-83 (1989).

28. Larsen TA, Olson AJ, Goodsell DS. Morphology of protein-protein interfaces. Structure 6(4), 421-427 (1998).

29. Keskin O, Gursoy A, Ma B, Nussinov R. Principles of protein-protein interactions: what are the preferred ways for proteins to interact? Chem. Rev. 108(4), 1225-1244 (2008).

30. Borgia A, Borgia MB, Bugge K et al. Extreme disorder in an ultrahigh-affinity protein complex. Nature 555(7694), 61-66 (2018).

31. Moffat JG, Rudolph J, Bailey D. Phenotypic screening in cancer drug discovery - past, present and future. Nat. Rev. Drug Discov. 13(8), 588-602 (2014).

32. Seijkens TTP, Van Tiel CM, Kusters PJH et al. Targeting CD40-induced TRAF6 signaling in macrophages reduces atherosclerosis. J. Am. Coll. Cardiol. 71(5), 527-542 (2018).

33. Von Hundelshausen P, Agten SM, Eckardt V et al. Chemokine interactome mapping enables tailored intervention in acute and chronic inflammation. Sci. Transl. Med. 9(384), eaah6650 (2017).

34. Wichapong K, Alard JE, Ortega-Gomez A et al. Structure-based design of peptidic inhibitors of the interaction between CC chemokine ligand 5 (CCL5) and human neutrophil peptides 1 (HNP1). J. Med. Chem. 59(9), 4289-4301 (2016). 
35. Alard JE, Ortega-Gomez A, Wichapong K et al. Recruitment of classical monocytes can be inhibited by disturbing heteromers of neutrophil HNP1 and platelet CCL5. Sci. Transl. Med. 7(317), 317ra196 (2015).

36. Zarzycka B, Seijkens T, Nabuurs SB et al. Discovery of small molecule CD40-TRAF6 inhibitors. J. Chem. Inf. Model. 55(2), 294-307 (2015).

37. Nicolaes GA, Kulharia M, Voorberg J et al. Rational design of small molecules targeting the C2 domain of coagulation factor VIII. Blood 123(1), 113-120 (2014).

38. Sperandio O, Wildhagen KC, Schrijver R, Wielders S, Villoutreix BO, Nicolaes GA. Identification of novel small molecule inhibitors of activated protein C. Thromb. Res. 133(6), 1105-1114 (2014).

39. Adrian M, Dubochet J, Lepault J, McDowall AW. Cryo-electron microscopy of viruses. Nature 308(5954), 32-36 (1984).

40. Renaud JP, Chari A, Ciferri C et al. Cryo-EM in drug discovery: achievements, limitations and prospects. Nat. Rev. Drug Discov. 17(7), 471-492 (2018).

41. Afanasyev P, Seer-Linnemayr C, Ravelli RBG et al. Single-particle cryo-EM using alignment by classification (ABC): the structure of Lumbricus terrestris haemoglobin. IUCrJ 4(Pt 5), 678-694 (2017).

42. Kobe B, Guncar G, Buchholz R et al. Crystallography and protein-protein interactions: biological interfaces and crystal contacts. Biochem. Soc. Trans. 36, 1438-1441 (2008).

43. Dafforn TR. So how do you know you have a macromolecular complex? Acta Crystallogr. Sect. D Biol. Crystallogr. 63, 17-25 (2007).

44. Lyubimov AY, Uervirojnangkoorn $\mathrm{M}$, Zeldin $\mathrm{OB}$ et al. Advances in $\mathrm{x}$-ray free electron laser (XFEL) diffraction data processing applied to the crystal structure of the synaptotagmin-1/SNARE complex. Elife 5, e18740 (2016).

45. Vaynberg J, Qin J. Weak protein Lumbricus terrestris protein interactions as probed by NMR spectroscopy. Trends Biotechnol. 24(1), 22-27 (2006).

46. Fort KL, Van De Waterbeemd M, Boll D et al. Expanding the structural analysis capabilities on an Orbitrap-based mass spectrometer for large macromolecular complexes. Analyst 143(1), 100-105 (2018).

47. D'arcy S, Martin KW, Panchenko $T$ et al. Chaperone Nap1 shields histone surfaces used in a nucleosome and can put H2A-H2B in an unconventional tetrameric form. Mol. Cell 51(5), 662-677 (2013).

48. Lossl P, Van De Waterbeemd M, Heck AJ. The diverse and expanding role of mass spectrometry in structural and molecular biology. EMBO. J. 35(24), 2634-2657 (2016).

49. Shen K, Huang RK, Brignole EJ et al. Architecture of the human GATOR1 and GATOR1-Rag GTPases complexes. Nature 556(7699), 64-69 (2018).

50. Bai XC, Yan C, Yang G et al. An atomic structure of human gamma-secretase. Nature 525(7568), 212-217 (2015).

51. Roh SH, Hryc CF, Jeong $\mathrm{HH}$ et al. Subunit conformational variation within individual GroEL oligomers resolved by Cryo-EM. Proc. Natl Acad. Sci. USA 114(31), 8259-8264 (2017).

52. Frank J. Generalized single-particle cryo-EM - a historical perspective. Microscopy (Oxf.) 65(1), 3-8 (2016). 


\section{Chapter 4}

53. Nogales E. The development of cryo-EM into a mainstream structural biology technique. Nat. Methods 13(1), 24-27 (2016).

54. Bartesaghi A, Merk A, Banerjee $S$ et al. 2.2 A resolution cryo-EM structure of beta-galactosidase in complex with a cell-permeant inhibitor. Science 348(6239), 1147-1151 (2015).

55. Timm DE, Bowman V, Madsen R, Rauch C. Cryo-electron microscopy structure of a human PRMT5:MEP50 complex. PLoS ONE 13(3), e0193205 (2018).

56. Arenz S, Bock LV, Graf M et al. A combined cryo-EM and molecular dynamics approach reveals the mechanism of ErmBL-mediated translation arrest. Nat. Commun. 712026 (2016).

57. Van Zundert GCP, Rodrigues J, Trellet M et al. The HADDOCK2.2 web server: user-friendly integrative modeling of biomolecular complexes. J. Mol. Biol. 428(4), 720-725 (2016).

58. Abagyan R, Totrov M, Kuznetsov D. ICM - a new method for protein modeling and design applications to docking and structure prediction from the distorted native conformation. J. Comput. Chem. 15(5), 488-506 (1994).

59. Pierce BG, Wiehe K, Hwang H, Kim BH, Vreven T, Weng Z. ZDOCK server: interactive docking prediction of protein-protein complexes and symmetric multimers. Bioinformatics 30(12), 1771-1773 (2014).

60. Yan Y, Zhang D, Zhou P, Li B, Huang SY. HDOCK: a web server for protein-protein and proteinDNA/RNA docking based on a hybrid strategy. Nucleic Acids Res. 45(W1), W365-W373 (2017).

61. Warren GL, Andrews CW, Capelli AM et al. A critical assessment of docking programs and scoring functions. J. Med. Chem. 49(20), 5912-5931 (2006).

62. Montalvao RW, Cavalli A, Salvatella X, Blundell TL, Vendruscolo M. Structure determination of protein-protein complexes using NMR chemical shifts: case of an endonuclease colicin-immunity protein complex. J. Am. Chem. Soc. 130(47), 15990-15996 (2008).

63. Miller MC, Ludwig AK, Wichapong K et al. Adhesion/growth-regulatory galectins tested in combination: evidence for formation of hybrids as heterodimers. Biochem. J. 475, 1003-1018 (2018).

64. Roberts VA, Pique ME, Hsu S, Li S. Combining H/D exchange mass spectrometry and computational docking to derive the structure of protein-protein complexes. Biochemistry 56(48), 6329-6342 (2017).

65. Wichapong K, Pianwanit S, Sippl W, Kokpol S. Homology modeling and molecular dynamics simulations of Dengue virus NS2B/NS3 protease: insight into molecular interaction. J. Mol. Recognit. 23(3), 283-300 (2010).

66. Loyau J, Didelot G, Malinge P et al. Robust antibody-antigen complexes prediction generated by combining sequence analyses, mutagenesis, in vitro evolution, $\mathrm{x}$-ray crystallography and in silico docking. J. Mol. Biol. 427(16), 2647-2662 (2015).

67. Shimba N, Kamiya N, Nakamura H. Model building of antibody-antigen complex structures using GBSA scores. J. Chem. Inf. Model. 56(10), 2005-2012 (2016).

68. Simoes ICM, Coimbra JTS, Neves RPP, Costa IPD, Ramos MJ, Fernandes PA. Properties that rank protein:protein docking poses with high accuracy. Phys. Chem. Chem. Phys. 20(32), 20927-20942 (2018). 
69. Rohe A, Erdmann F, Bassler C, Wichapong K, Sippl W, Schmidt M. In vitro and in silico studies on substrate recognition and acceptance of human PKMYT1, a Cdk1 inhibitory kinase. Bioorg. Med. Chem. Lett. 22(2), 1219-1223 (2012).

70. Tovchigrechko A, Vakser IA. How common is the funnel-like energy landscape in protein-protein interactions? Protein Sci. 10(8), 1572-1583 (2001).

71. Miller BR, McGee TD, Swails JM, Homeyer N, Gohlke H, Roitberg AE. MMPBSA.py: an efficient program for end-state free energy calculations. J. Chem. Theory Comput. 8(9), 3314-3321 (2012).

72. Tsomaia N. Peptide therapeutics: targeting the undruggable space. Eur. J. Med. Chem. 94, 459-470 (2015).

73. Fosgerau K, Hoffmann T. Peptide therapeutics: current status and future directions. Drug Discov. Today 20(1), 122-128 (2015).

74. Lau JL, Dunn MK. Therapeutic peptides: historical perspectives, current development trends, and future directions. Bioorg. Med. Chem. 26(10), 2700-2707 (2018).

75. Pelay-Gimeno M, Glas A, Koch O, Grossmann TN. Structure-based design of inhibitors of proteinprotein interactions: mimicking peptide binding epitopes. Angew. Chem. Int. Ed. Engl. 54(31), 8896-8927 (2015).

76. Cunningham BC, Wells JA. High-resolution epitope mapping of hGH-receptor interactions by alanine-scanning mutagenesis. Science 244(4908), 1081-1085 (1989).

77. Clackson T, Wells JA. A hot spot of binding energy in a hormone-receptor interface. Science 267(5196), 383-386 (1995).

78. Henninot A, Collins JC, Nuss JM. The current state of peptide drug discovery: back to the future? J. Med. Chem. 61(4), 1382-1414 (2018).

79. Hummel G, Reineke U, Reimer U. Translating peptides into small molecules. Mol. Biosyst. 2(10), 499-508 (2006).

80. Ripka AS, Rich DH. Peptidomimetic design. Curr. Opin. Chem. Biol. 2(4), 441-452 (1998).

81. Diller DJ, Swanson J, Bayden AS, Jarosinski M, Audie J. Rational, computer-enabled peptide drug design: principles, methods, applications and future directions. Future Med. Chem. 7(16), 2173-2193 (2015)

82. Ciemny M, Kurcinski M, Kamel K et al. Protein-peptide docking: opportunities and challenges. Drug Discov. Today 23(8), 1530-1537 (2018).

83. Trott O, Olson AJ. AutoDock Vina: improving the speed and accuracy of docking with a new scoring function, efficient optimization, and multithreading. J. Comput. Chem. 31(2), 455-461 (2010).

84. Jones G, Willett P, Glen RC, Leach AR, Taylor R. Development and validation of a genetic algorithm for flexible docking. J. Mol. Biol. 267(3), 727-748 (1997).

85. Friesner RA, Banks JL, Murphy RB et al. Glide: a new approach for rapid, accurate docking and scoring. 1. Method and assessment of docking accuracy. J. Med. Chem. 47(7), 1739-1749 (2004).

86. Spitzer R, Jain AN. Surflex-dock: docking benchmarks and real-world application. J. Comput. Aided Mol. Des. 26(6), 687-699 (2012).

87. Zhou P, Wang C, Ren Y, Yang C, Tian F. Computational peptidology: a new and promising approach to therapeutic peptide design. Curr. Med. Chem. 20(15), 1985-1996 (2013). 
88. Tian F, Lv Y, Zhou P, Yang L. Characterization of PDZ domain-peptide interactions using an integrated protocol of QM/MM, PB/SA, and CFEA analyses. J. Comput. Aided Mol. Des. 25(10), 947-958 (2011)

89. Jiang SJ, Liou JW, Chang CC, Chung Y, Lin LF, Hsu HJ. Peptides derived from CXCL8 based on in silico analysis inhibit CXCL8 interactions with its receptor XCR1. Sci. Rep. 518638 (2015).

90. Greene D, Po T, Pan J, Tabibian T, Luo R. Computational analysis for the rational design of antiamyloid beta (Abeta) antibodies. J. Phys. Chem. B 122(16), 4521-4536 (2018).

91. Wang C, Greene D, Xiao L, Qi R, Luo R. Recent developments and applications of the MMPBSA method. Front. Mol. Biosci. 4, 87 (2017).

92. Gentilucci L, De Marco R, Cerisoli L. Chemical modifications designed to improve peptide stability: incorporation of non-natural amino acids, pseudo-peptide bonds, and cyclization. Curr. Pharm. Des. 16(28), 3185-3203 (2010).

93. Thapa P, Espiritu MJ, Cabalteja C, Bingham JP. The emergence of cyclic peptides: the potential of bioengineered peptide drugs. Int. J. Pept. Res. Ther. 20(4), 545-551 (2014).

94. Driggers EM, Hale SP, Lee J, Terrett NK. The exploration of macrocycles for drug discovery - an underexploited structural class. Nat. Rev. Drug Discov. 7(7), 608-624 (2008).

95. Shaabani S, Huizinga HPS, Butera R et al. A patent review on PD-1/PD-L1 antagonists: small molecules, peptides, and macrocycles (2015-2018). Expert Opin. Ther. Pat. 28(9), 665-678 (2018).

96. Kundu R, Cushing PR, Popp BV, Zhao Y, Madden DR, Ball ZT. Hybrid organic-inorganic inhibitors of a PDZ interaction that regulates the endocytic fate of CFTR. Angew. Chem. Int. Ed. Engl. 51(29), 7217-7220 (2012).

97. Richelle GJJ, Ori S, Hiemstra H, Van Maarseveen JH, Timmerman P. General and facile route to isomerically pure tricyclic peptides based on templated tandem CLIPS/CuAAC cyclizations. Angew. Chem. Int. Ed. Engl. 57(2), 501-505 (2017).

98. Van Maarseveen JH, Timmerman P. Editorial for the special issue on 'constrained peptides'. Drug Discov. Today Technol. 26, 1-2 (2017).

99. Bernal F, Tyler AF, Korsmeyer SJ, Walensky LD, Verdine GL. Reactivation of the p53 tumor suppressor pathway by a stapled p53 peptide. J. Am. Chem. Soc. 129(9), 2456-2457 (2007).

100. Chorev M, Goodman M. A dozen years of retro-inverso peptidomimetics. Acc. Chem. Res. 26(5), 266-273 (1993).

101. Zuckermann RN. Peptoid origins. Biopolymers 96(5), 545-555 (2011).

102. Kessler H. Peptoids - a new approach to the development of pharmaceuticals. Angew. Chem. Int. Ed. Engl. 32(4), 543-544 (1993).

103. Bohacek RS, Mcmartin C. Multiple highly diverse structures complementary to enzyme binding-sitesresults of extensive application of a De-Novo design method incorporating combinatorial growth. $J$. Am. Chem. Soc. 116(13), 5560-5571 (1994).

104. Floris M, Moro S. Mimicking peptides. . in silico. Mol. Inform. 31(1), 12-20 (2012).

105. Floris M, Masciocchi J, Fanton M, Moro S. Swimming into peptidomimetic chemical space using pepMMsMIMIC. Nucleic Acids Res. 39, W261-W269 (2011). 
106. Bond GL, Hu WW, Levine AJ. MDM2 is a central node in the $\mathrm{p} 53$ pathway: 12 years and counting. Curr. Cancer Drug Targets 5(1), 3-8 (2005).

107. Kussie PH, Gorina S, Marechal V et al. Structure of the MDM2 oncoprotein bound to the $\mathrm{p} 53$ tumor suppressor transactivation domain. Science 274(5289), 948-953 (1996).

108. Nayak SK, Khatik GL, Narang R, Monga V, Chopra HK. p53-Mdm2 interaction inhibitors as novel nongenotoxic anticancer agents. Curr. Cancer Drug Targets 18(8), 749-772 (2018).

109. Ding K, Lu Y, Nikolovska-Coleska $Z$ et al. Structure-based design of potent non-peptide MDM2 inhibitors. J. Am. Chem. Soc. 127(29), 10130-10131 (2005).

110. Vaux DL, Cory S, Adams JM. Bcl-2 gene promotes haemopoietic cell survival and cooperates with c-.Myc to immortalize pre-B cells. Nature 335(6189), 440-442 (1988).

111. Sattler M, Liang H, Nettesheim D et al. Structure of Bcl-xL-Bak peptide complex: recognition between regulators of apoptosis. Science 275(5302), 983-986 (1997).

112. Lomonosova E, Chinnadurai G. BH3-only proteins in apoptosis and beyond: an overview. Oncogene 27(Suppl. 1), S2-S19 (2008).

113. Nguyen M, Marcellus RC, Roulston A et al. Small molecule obatoclax (GX15-070) antagonizes MCL-1 and overcomes MCL-1-mediated resistance to apoptosis. Proc. Natl Acad. Sci. USA 104(49), 19512-19517 (2007).

114. Oltersdorf T, Elmore SW, Shoemaker AR et al. An inhibitor of $\mathrm{Bcl}-2$ family proteins induces regression of solid tumours. Nature 435(7042), 677-681 (2005).

115. Tse C, Shoemaker AR, Adickes J et al. ABT-263: a potent and orally bioavailable Bcl-2 family inhibitor. Cancer Res. 68(9), 3421-3428 (2008).

116. Souers AJ, Leverson JD, Boghaert ER et al. ABT-199, a potent and selective BCL-2 inhibitor, achieves antitumor activity while sparing platelets. Nat. Med. 19(2), 202-208 (2013).

117. Cohen NA, Stewart ML, Gavathiotis E et al. A competitive stapled peptide screen identifies a selective small molecule that overcomes MCL-1-dependent leukemia cell survival. Chem. Biol. 19(9), 1175-1186 (2012).

118. Gavathiotis E, Reyna DE, Bellairs JA, Leshchiner ES, Walensky LD. Direct and selective small-molecule activation of proapoptotic BAX. Nat. Chem. Biol. 8(7), 639-645 (2012).

119. Tuszynski GP, Cossu G. Differential cytotoxic effect of gossypol on human melanoma, colon carcinoma, and other tissue culture cell lines. Cancer Res. 44(2), 768-771 (1984).

120. Wei J, Kitada S, Rega MF et al. Apogossypol derivatives as antagonists of antiapoptotic Bcl-2 family proteins. Mol. Cancer Ther. 8(4), 904-913 (2009).

121. Berman HM, Westbrook J, Feng Z et al. The protein data bank. Nucleic Acids Res. 28(1), 235-242 (2000)

122. Liou JW, Chang FT, Chung Y, Chen WY, Fischer WB, Hsu HJ. In silico analysis reveals sequential interactions and protein conformational changes during the binding of chemokine CXCL-8 to its receptor CXCR1. PLoS ONE 9(4), e94178 (2014).

123. Koenen RR, Von Hundelshausen P, Nesmelova IV et al. Disrupting functional interactions between platelet chemokines inhibits atherosclerosis in hyperlipidemic mice. Nat. Med. 15(1), 97-103 (2009). 


\section{Chapter 4}

124. Hermeking H, Benzinger A. 14-3-3 proteins in cell cycle regulation. Semin. Cancer Biol. 16(3), 183-192 (2006).

125. Ballone A, Centorrino F, Ottmann C. 14-3-3: a case study in PPI modulation. Molecules 23(6), (2018).

126. Andrei SA, Meijer FA, Neves JF et al. Inhibition of 14-3-3/Tau by hybrid small-molecule peptides operating via two different binding modes. ACS Chem. Neurosci.(9(11), 2639-2654 (2018).

127. Andrei SA, De Vink P, Sijbesma E et al. Rationally designed semisynthetic natural product analogues for stabilization of 14-3-3 protein-protein interactions. Angew Chem. Int. Ed. Engl. 57(41), 13470-13474 (2018).

128. Chou CC, Lunn CA, Murgolo NJ. KCa3.1: target and marker for cancer, autoimmune disorder and vascular inflammation? Expert Rev. Mol. Diagn. 8(2), 179-187 (2008).

129. Zhang M, Pascal JM, Schumann M, Armen RS, Zhang JF. Identification of the functional binding pocket for compounds targeting small-conductance Ca2+-activated potassium channels. Nat. Commun. 3, 1021 (2012).

130. Chen J, Kriwacki RW. Intrinsically disordered proteins: structure, function and therapeutics. J. Mol. Biol. 430(16), 2275-2277 (2018).

131. Collepardo-Guevara R, Portella G, Vendruscolo M, Frenkel D, Schlick T, Orozco M. Chromatin unfolding by epigenetic modifications explained by dramatic impairment of internucleosome interactions: a multiscale computational study. J. Am. Chem. Soc. 137(32), 10205-10215 (2015).

132. Chong SH, Chatterjee P, Ham S. Computer simulations of intrinsically disordered proteins. Annu. Rev. Phys. Chem. 68, 117-134 (2017).

133. Huang J, MacKerell AD, Jr. Force field development and simulations of intrinsically disordered proteins. Curr. Opin. Struct. Biol. 48, 40-48 (2018)

134. Kmiecik S, Gront D, Kolinski M, Wieteska L, Dawid AE, Kolinski A. Coarse-grained protein models and their applications. Chem. Rev. 116(14), 7898-7936 (2016).

135. Baaden M, Marrink SJ. Coarse-grain modelling of protein-protein interactions. Curr. Opin. Struct. Biol. 23(6), 878-886 (2013).

136. Zinzalla G. Targeting MYC: is it getting any easier? Future Med. Chem. 8(16), 1899-1902 (2016).

137. Soucek L, Whitfield J, Martins CP et al. Modelling Myc inhibition as a cancer therapy. Nature 455(7213), 679-683 (2008).

138. Harvey SR, Porrini M, Stachl C, MacMillan D, Zinzalla G, Barran PE. Small-molecule inhibition of c-MYC:MAX leucine zipper formation is revealed by ion mobility mass spectrometry. J. Am. Chem. Soc. 134(47), 19384-19392 (2012).

139. Yin XY, Giap C, Lazo JS, Prochownik EV. Low molecular weight inhibitors of Myc-Max interaction and function. Oncogene 22(40), 6151-6159 (2003).

140. Sammak S, Zinzalla G. Targeting protein-protein interactions (PPIs) of transcription factors: challenges of intrinsically disordered proteins (IDPs) and regions (IDRs). Prog. Biophys. Mol. Biol. 119(1), 41-46 (2015).

141. Savino M, Annibali D, Carucci $\mathrm{N}$ et al. The action mechanism of the Myc inhibitor termed Omomyc may give clues on how to target Myc for cancer therapy. PLoS ONE 6(7), e22284 (2011). 
142. Soucek L, Jucker R, Panacchia L, Ricordy R, Tato F, Nasi S. Omomyc, a potential Myc dominant negative, enhances Myc-induced apoptosis. Cancer Res. 62(12), 3507-3510 (2002).

143. Kumar D, Sharma N, Giri R. Therapeutic interventions of cancers using intrinsically disordered proteins as drug targets: c-Myc as model system. Cancer Informatics 16, 1176935117699408 (2017).

144. Metallo SJ. Intrinsically disordered proteins are potential drug targets. Curr. Opin. Chem. Biol. 14(4), 481-488 (2010).

145. Tsafou K, Tiwari PB, Forman-Kay JD, Metallo SJ, Toretsky JA. Targeting intrinsically disordered transcription factors: changing the paradigm. J. Mol. Biol. 430(16), 2321-2341 (2018).

146. Chen CY, Tou WI. How to design a drug for the disordered proteins? Drug Discov. Today 18(19-20), 910-915 (2013).

147. Michel J, Cuchillo R. The impact of small molecule binding on the energy landscape of the intrinsically disordered protein C-myc. PLoSONE 7(7), e41070 (2012).

148. Salomon-Ferrer R, Gotz AW, Poole D, Le Grand S, Walker RC. Routine microsecond molecular dynamics simulations with AMBER on GPUs. 2. Explicit solvent particle mesh Ewald. J. Chem. Theory Comput. 9(9), 3878-3888 (2013).

149. Gotz AW, Williamson MJ, Xu D, Poole D, Le Grand S, Walker RC. Routine microsecond molecular dynamics simulations with AMBER on GPUs. 1. Generalized born. J. Chem. Theory Comput. 8(5), 1542-1555 (2012). 